\title{
Effects of use on the hydraulic resistance of drainage conduits
}

\author{
by \\ P. Ackers, M.Sc.(Eng.), A.M.I.C.E., A.M.I.Mun.E. \\ M. J. Crickmore, B.A. \\ and \\ D. W. Holmes, B.Sc.(Eng.)
}

Mr J. B. White (Department of Municipal Engineering, University of Manchester) wrote that now the Authors had shown that the extent of slime has a significant effect on the flow-carrying capacity of sewers, it seemed necessary to differentiate between the types of sewer with which the designer had to deal. Presumably the relative amount of slime to be allowed for should be greater for foul sewers on the separate system than for combined sewers. Perhaps slime could be neglected in designing surface-water sewers, though if velocities were low, some allowance should be made for silting. Could storm-water overflow pipes be treated in the same way as surfacewater sewers or was slime likely to form in them?

44. If there was likely to be a significant difference between foul and combined sewers, it would be useful if the Authors could give the type of each sewer which was tested. Since 'foul' was a somewhat relative term, though, the best course might be to give the depth corresponding to dry-weather flow in each case.

45. Most of the tests reported were carried out at low relative depths of flow. In the cases where the test flow was of the same order as dry-weather flow, was it likely that the pipes would have lower equivalent values of $k_{\mathrm{s}}$ when flowing nearly full?

46. Further investigations would seem to be desirable to find to what extent the incidence of sliming differed in foul, combined, surface-water, and storm-water overflow sewers and also in rising mains and inverted syphons. Even visual inspection of a number of pipes in each category would be of value.

Mr L. B. Escritt (Assistant Senior Engineer, London County Council) wrote that the factors which influenced turbulent flow in pipes were too complex to be expressed accurately and adequately by any existing formula that satisfied theorists. They included local changes of diameter and gradient, joints and excrescences in addition to the 'roughness' usually mentioned in the literature. However, hydraulic phenomena, when plotted on logarithmic ordinates and abscissae, almost invariably gave straight lines and this was true of the flow of water in pipes. Hydraulic radius, hydraulic gradient and velocity were accurately related by the empiric formula:

$$
V=K m^{\alpha} i^{s}
$$

where $V=$ velocity in $\mathrm{ft} / \mathrm{s}, m=$ hydraulic radius in $\mathrm{ft}, i=$ fall divided by length, and $K=$ a constant.

48. The values of $K, \alpha$, and $\beta$ all varied according to the nature of the pipe or channel, and this was factual in spite of any theoretical objection that $\alpha$ should be constant and $\beta$ could not vary from 0.5 . This variation had been proved by many careful experiments in which the plotted data formed straight lines on logarithmic paper. An exception occurred when the power of $m$ was found by plotting the results

* Proc. Instn civ. Engrs, 1964, 28 (July), 339-60. 


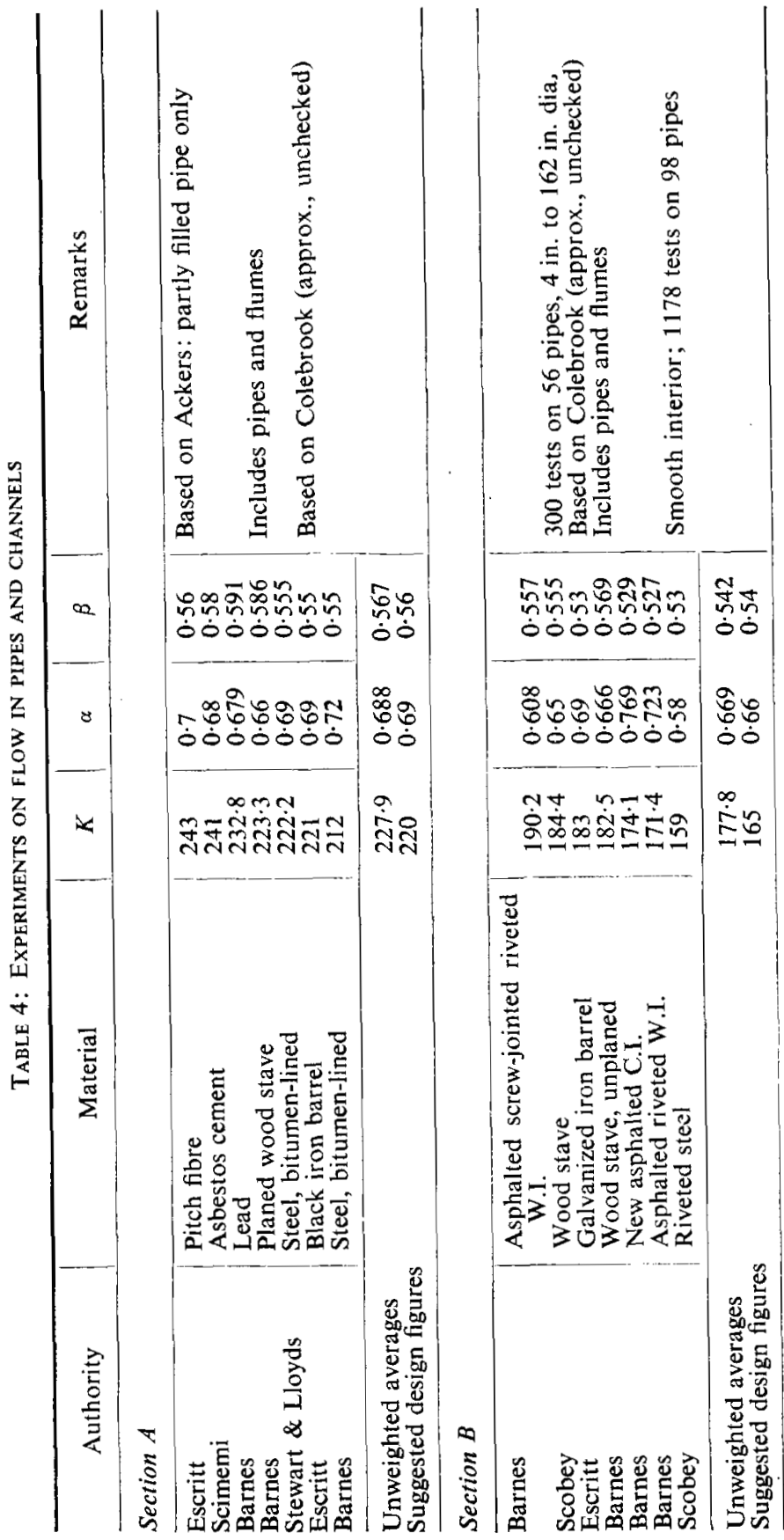




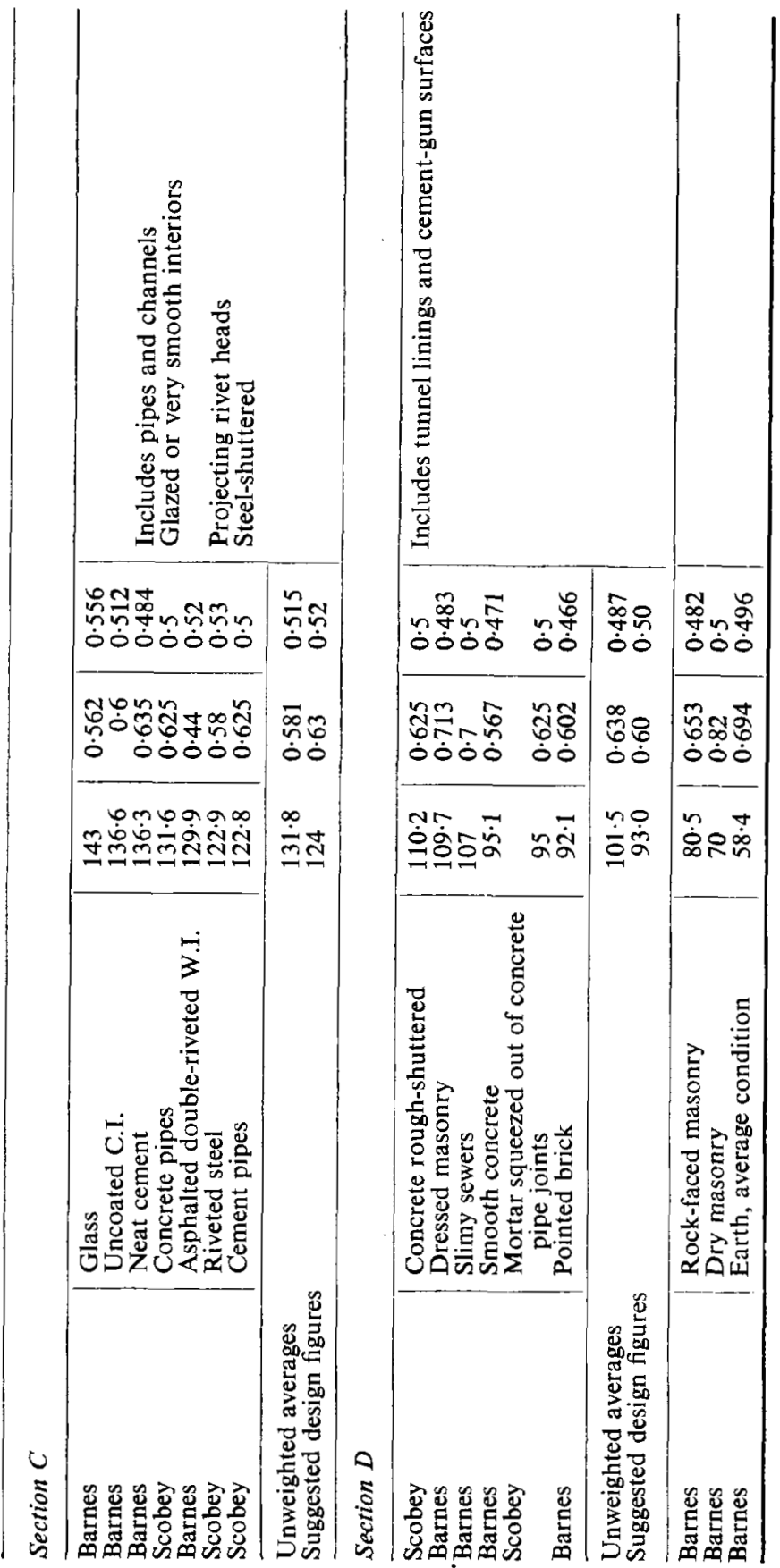


of pipes running partly full: this, no doubt, was because the friction between air and water was neglected when determining the hydraulic mean depth.

49. A fair cross section of existing data was given in Table 4 which was based on vast numbers of tests made by several experimenters. Section $A$ was for pipes with very smooth interiors, constant cross-sectional areas, and infrequent joints. In these circumstances there was little variation in $\alpha$ and $\beta$ from an average value.

50. Section $\mathbf{B}$ was for new pipe lines of good construction, and Section $\mathbf{C}$ for the general standard of engineering manufacture and construction. Section D was for old fouled sewers, rough-shuttered concrete, brickwork, etc.

51. When examining scientific data it was often observed that there were regularities, frequently occurring figures, and correlations. These could be accidental or they could have significance which, if appreciated, could lead to further discoveries. It was found that the tests plotted in Table 4 fell into groups spaced apart and occurring at fairly regular intervals: this had no mathematical significance but proved convenient. It was also found that the values of $\alpha$ and $\beta$ reasonably approximated to a function of $K$; there appeared to be a scientific reason for this which, however, was not brought to light.

52. In addition to the data, suggestions were given in Table 4 as to general formulae based thereon which could be used for the preparation of graphs or tables for design purposes.

53. The tests described in the Paper gave some confirmation to the figures in Table 4. Neglecting sites 5, 12 and 13, the data for which were not expressed in a form that could be safely used, the average of the remaining results agreed very closely with Barnes' formula for flow in slimy sewers, suggesting that this gave a fair estimate of flow in old and dirty sewers.

54. However, when a sewer or sewage rising main ran most of the time at a velocity too low to keep it clean, silt accumulated in the invert and scum at normal top water level, but it was correct to allow for cleansing velocities at normal daily flows when designing. Accordingly it was legitimate, when considering research from the point of view of its bearing on design, to exclude data for tests where velocities were less than required for clean conditions-i.e. the tests at sites $2,4,6,15$, 16 and 18 . When this was done it was found that the results conformed very well with Scobey's formula for concrete sewers and tunnel linings.

Mr W. V. Clay (Assistant Designing Engineer, Drainage Division, Auckland Regional Authority, New Zealand) wrote that observations made in Auckland were in general agreement with those of the Authors and might be of interest.

56. Measurements were made in a sewer 12 miles long, varying from 85 in. dia. to 102 in. semi-elliptical. The sewer was concrete, cast in place against steel forms and with any roughness ground off. The first set of measurements were made 2 months after the sewer was brought into use, with a sewage flow of 29.4 cusec and hydraulic radii of $0.89-1.20 \mathrm{ft}$, and velocities of $2 \cdot 7-3.8 \mathrm{ft} / \mathrm{s}$. The average surface roughness was $k_{\mathrm{g}}=0.0021$, obtained from measurements at 22 places along the sewer. At individual sites, the roughness appeared to vary from 0.0007 to 0.015 .

57. Measurements were repeated at 11 places on the $85 \mathrm{in}$. section of this sewer after it had been in use 11 months. The sewage flow used was $80 \cdot 3$ cusec and the hydraulic radii were $1 \cdot 70-1 \cdot 87 \mathrm{ft}$ and velocities of $3 \cdot 6-4 \cdot 4 \mathrm{ft} / \mathrm{s}$. The average surface roughness was $k_{\mathrm{s}}=0.0059$ with a variation from 0.0034 to 0.0079 . This higher roughness appeared to be related to the sliming of the sewer. At that time there was a film of slime over the bottom of the sewer and $\frac{1}{8}$ in. to $\frac{1}{4}$ in. of slime near the normal water level. In each set of measurements a constant flow was pumped into the sewer for a number of hours to ensure that steady conditions were obtained. The flow was measured by a Venturi tube, and the roughnesses were calculated from measurements of the cross sections of flow and water levels. 
TABLE 5

\begin{tabular}{|c|c|c|c|c|c|c|}
\hline Site & $\begin{array}{c}\text { Material of } \\
\text { construction }\end{array}$ & $\begin{array}{c}\text { Age } \\
\text { months }\end{array}$ & $\begin{array}{l}\text { Dia. } \\
\text { in. }\end{array}$ & $\begin{array}{l}\text { Length } \\
f t\end{array}$ & $\begin{array}{c}\text { Velocity } \\
\mathrm{ft} / \mathrm{s}\end{array}$ & $\begin{array}{c}\text { Roughness } \\
f t\end{array}$ \\
\hline Otara & $\begin{array}{l}8 \mathrm{ft} \text { long spun con- } \\
\text { crete pipes }\end{array}$ & 10 & 25 & 5805 & $\begin{array}{l}4 \cdot 78 \\
5 \cdot 25\end{array}$ & $\begin{array}{l}0.00029 \\
0.00014\end{array}$ \\
\hline Pt England & " & 24 & $18 \frac{1}{2}$ & 2642 & $\begin{array}{l}2 \cdot 57 \\
5 \cdot 54\end{array}$ & $\begin{array}{l}0.00064 \\
0.00118\end{array}$ \\
\hline Kohimarama & , & 15 & 11 & 1189 & $\begin{array}{l}4 \cdot 91 \\
5 \cdot 03 \\
8.73 \\
8 \cdot 85 \\
8.97\end{array}$ & $\begin{array}{l}0.00024 \\
0.00025 \\
0.00028 \\
0.00025 \\
0.00022\end{array}$ \\
\hline
\end{tabular}

58. Roughnesses were also calculated from measurements of pressure drop on some long pressure sewers and after allowing for extraneous pressure losses the results given in Table 5 were obtained.

59. There appeared to be a correlation between the age of the pressure sewer and the roughness.

Mr D. H. Cassidy (Assistant Senior Engineer, Chief Engineer's Department, London County Council) wrote that the following notes on some methods used in the design of main sewers in the County of London reviewed in the light of figures given in the Authors' Paper might be of interest. When considering improvements in the drainage of an area it was, of course, not only necessary to decide on the sizes of new sewers but to estimate the capacities of existing ones. Most of the old sewers in the county were of brick, and the condition varied from smooth close-jointed work almost like new, to rough eroded brickwork with joints requiring pointing. Silt was frequently present. Nevertheless for many years the tables of Crimp and Bruges had been used for estimating the capacities of both old and new sewers. Some 15 years ago, however, the dry-weather flow at a number of points was measured using the saltvelocity method, and it was noted that the velocities were lower, and often considerably lower, than would have been given by Crimp and Bruges. As a result it was decided that in estimating the capacities of existing sewers for storm flow (the system was combined), a value of $80 \%$ of that given by Crimp and Bruges should be used. This was considered to be a conservative figure, as the condition of the invert would normally be worse than that of the whole section. This view could not, however, be supported by the figures given in Hydraulics Research Paper No. 4 and in the Authors' Paper. Taking as an example a $5 \mathrm{ft}$ diameter brick sewer at a grade of $1 / 417$, the discharges for good, normal, and poor brickwork, and for brickwork requiring repointing (normal), would be $88,81,73$ and $64 \%$ respectively of the Crimp and Bruges figures. Sliming would cause further reductions in some of the cases, and deposits would have an even greater effect in all of them. It was evident then that when evaluating the capacity of an existing system, more note would have to be taken of the condition of the individual sewers.

61. Some new sewers had been designed on the same basis of $80 \%$ of the capacity given by Crimp and Bruges, to allow for ageing, but some years ago this was modified to $95 \%$, equivalent to the results given by Manning's formula with a value of 0.013 for $n$, on the grounds that as the sewers were either combined or for storm sewage, wear would only have a small effect or would be negligible and that grit should not collect in a properly designed sewer. Taking as an example a $7 \mathrm{ft} 4$ in. dia. combined 
sewer recently constructed in tunnel but assuming for convenience for use of the Hydraulics Research Tables that its size and grade were $7 \mathrm{ft}$ and $1 / 833$ respectively, the discharge by Manning's formula would be 221 cusec. This sewer had a brick invert of $120^{\circ}$ of the circumference and the remainder of the perimeter was of concrete placed against laggings and bagged down. There was the difficulty of fixing a value of $k_{\mathrm{g}}$ for this surface which was slightly uneven and with a grain of the order of $0.002 \mathrm{ft}$, but using the latter figure and one of $0.005 \mathrm{ft}$ for brickwork, the composite roughness was $0.003 \mathrm{ft}$. Interpolating between the tables gave a discharge of 223 cusec, practically the same as Manning. Normal sliming of the invert to not more than $\frac{1}{4}$ in. over the $6.5 \mathrm{ft}$ of the perimeter wetted by dry-weather flow would not affect the capacity, as the Authors' value of $k_{\mathrm{s}}$ for this was $0.005 \mathrm{ft}$. If the $k_{\mathrm{s}}$ value for the invert were to be increased to $0.01 \mathrm{ft}$ the capacity would be reduced by about $4 \%$ which would not appear to be serious because of the other uncertainties of design. If the $k_{s}$ value should become $0.05 \mathrm{ft}$ the capacity would be reduced to about $82 \%$ of the sewer when new and this could not be neglected.

62. It was considered, however, that this condition would hardly be reached until the joints in the brickwork had deteriorated, and that this would not happen for a long period of time. In this connexion it should be noted that brickwork was used in the invert for ease of repair. It was concluded therefore that the design size of the sewer was satisfactory. One point that was not quite clear, however, was whether the terms 'good', 'normal' and 'poor' in Table 3 referred to the state of the sliming or to the original quality of the workmanship.

63. When a sewer was to be constructed in tunnel the size given by the flow formula used nearly always had to be modified to suit the standard sizes of precast concrete or cast iron segments, or because it was not generally economical to construct in tunnel a sewer smaller than about $5 \mathrm{ft}$ diameter or to change the size of a run of sewer when a shield had to be used. This generally resulted in the size of the sewer being increased, and in practice this had probably helped to cover ageing effects and the many other uncertainties in the design of combined sewers of the type just described.

64. Anyone acquainted with drainage work knew the difficulties and unpleasantness involved in trying to make measurements in sewers, and Mr Ackers deserved the thanks of engineers for his efforts to replace guesswork by ascertained facts.

Dr D. I. H. Barr and Mr A. A. Smith (Department of Civil Engineering, University of Strathclyde) wrote that the Paper was the latest of a series on flow resistance in pipes and channels with which Mr Ackers had been associated, previously as sole author. The Paper was stated to be a sequel to an earlier paper ${ }^{1}$ and it depended on the premises given previously. It was regrettable that the first paper had attracted only one discussion, albeit from Dr C. Colebrook. It in turn had been preceded by Hydraulics Research Paper No. $\mathbf{1}^{2}$ where direct discussion was not possible. Dr Barr and $\mathrm{Mr}$ Smith thus felt justified in dealing not only with the present Paper, but also with the essential background to it as given in these earlier papers.

66. An argument had been given which led from the work of Von Karman, Prandtl, and Nikuradse to the Hydraulics Research Station design charts by way of the Colebrook-White transition equation. The writers felt that the charts were of considerable value in their present form but that the argument mitigated against the general adoption of the charts and, more important, their revision as greater understanding of the problem of flow resistance was obtained. The writers' alternative approach would be presented in detail elsewhere, but they had already touched on it in the discussion of a previous paper ${ }^{13}$ and they felt that the Authors should also have an opportunity to comment.

67. In the Paper under discussion, a form of free surface Froude number was defined and was utilized to correlate results from sewers running part full. It should be realized that the Darcy-Weisbach friction factor was essentially another form of 
Froude number, appropriate to steady uniform flow. Once this was recognized the path was open for synthesis of all types of general similarity equation and resistance diagram parameters associated with uniform flow, including those utilized by $\mathrm{Mr}$ Ackers in his design charts, by means of a very straightforward similarity argument which completely bypassed all the analytical and semi-analytical work on resistance laws.

68. An outline of this argument was as follows. The component of gravitational acceleration in the mean direction of flow in an open channel where uniform flow obtained was $S g$, where $S$ was the slope of the channel and equally the linear rate of head loss, and $g$ the acceleration due to gravity. It would be seen that, for incompressible flow in a uniform closed conduit, the equivalent approach was to seek the value of force, acting along the conduit, which was necessary to maintain uniform flow. This was again defined by an acceleration $S g$ where $S=h / l, h$ being the loss of piezometric head over a length of conduit $l$, and in terms of the fluid flowing. Since steady turbulent flow in a uniform conduit was accelerative, the standard derivation of basic dimensionless groups was appropriate, i.e. the criterion for dynamic similarity between two comparable systems in respect of a single active force was that the ratio of the active forces to the inertial forces on corresponding elements should be the same in both cases. Hence by the standard method and taking the case of a pipe of diameter $d$, the normal pipe Froude number $V / \sqrt{ }(S g d)$, or, for rough pipes, the pipe roughness Froude number, $V / \sqrt{ }(S g k)$ could be obtained as could the normal pipe Reynolds number $V d / \nu$ or the pipe roughness Reynolds number $V k / \nu$, where $V$ was the mean velocity, $k$ was the equivalent sand roughness or any other dimension uniquely defining a systematic variation of boundary form, and $v$ was the kinematic viscosity.

69. One thus had three types of velocity variable (in basic form, $V, \sqrt{ }(S g d)$ and $v / d$ ) and with the introduction of a second linear variable $k$, one could substitute $k$ for $d$ in the velocity variables, yet preserve unique definition of the flow circumstances by the statement of the $k / d$ ratio. The foundation was thus laid for general similarity equations of various types, including:

(a) $f\left(\frac{V}{\sqrt{ }(S g d)}, \frac{V}{\nu / d}, \frac{k}{d}\right)=0$ the basis of the Stanton diagram;

(b) $f\left(\frac{V}{\sqrt{ }(S g m)}, \frac{\sqrt{ }(S g m)}{v / m}, \frac{k}{m}\right)=0$ the basis of the Johnson/Langhaar diagram;

(c) $f\left(\frac{V}{\nu / k}, \frac{\sqrt{ }(S g k)}{v / k}, \frac{k}{m}\right)=0$ the basis of the Ackers diagram;

(the substitution of hydraulic mean depth, $m$, for $d$ had, of course, no significance provided overall geometric similarity was maintained).

70. The writers felt that the independence of the Johnson/Langhaar diagram and the Ackers diagram parameters, from the Colebrook-White formula and even from the smooth and the rough pipe logarithmic resistance formula, and their dependence on basic reasoning (not dimensional analysis) should be emphasized. The fact that these formulae could be written in terms of the parameters was an argument for the formulae-by no means a conclusive argument-and not an argument for the parameters which needed no support or justification.

71. The writers wished to stress the importance of the contribution of Johnson, ${ }^{14}$ Rouse, ${ }^{15}$ and Langhaar ${ }^{16}$ to the development of diagrams from which direct solutions for the second of the three "standard'17 pipe flow problems could be obtained. Of particular interest was the fact that Langhaar directly substituted $V / \sqrt{ }(\mathbf{S g m})$ for the Darcy-Weisbach friction factor. Ackers ${ }^{1}$ had mentioned Powell ${ }^{18}$ as also suggesting the substitution of $k$ for $d$ or $m$ as the repeating linear variable, but the writers felt that the main credit for showing the value of this approach was due to $\mathrm{Mr}$ Ackers. 
72. In considering the effect of sliming and of accretion of solids on the carrying capacity of a sewer there were two distinct factors; the cross-sectional area became smaller, and the character of the new effective boundary changed from that of the original boundary. If one wished to make an approach which had promise of consistency when carried to extreme cases, it appeared essential to separate these two effects. While in most of the cases quoted in the Paper, this was a minor point, the inclusion of cases such as sites 6 and 17 made valid questions as to the Authors' approach in this matter. The writers understood that in seeking the equivalent sand roughness, the value desired was that which would give the same rate of energy dissipation without change in the quantity of liquid within a given reach, or of the hydraulic mean depth based on the mean boundary position. Site 6 appeared to illustrate the uncertainties of extrapolating Nikuradse's result from the maximum $d / k$ value of 30 used by him to values of the arder of 3 which was suggested by the data obtained from site 6 . Here an equivalent $k$ of $0.4 \mathrm{ft}$ with $m=0.248 \mathrm{ft}$ was found necessary to justify the energy losses resulting in a reach with standing waves and pebbles of approximately 2 in. diameter. Nikuradse's aim was to gain understanding of rough pipe flow and not to establish a standard of roughness measurement. The results of an attempt to check the assessment of equivalent sand roughness by an actual reconstruction would doubtless be most enlightening. One would probably have to convert to the case of a very wide flat bottomed channel. Whether the $0.4 \mathrm{ft}$ roughness elements would be submerged or not in the $0.248 \mathrm{ft}$ depth was open to question. Certainly the submergence would be slight, even allowing for the effect of the scaled up laquer thickness.

73. It might be thought that the writers were taking an absurd example. But Fig. 5 was taken to the case of $d / k=1$ or $m / k=0 \cdot 25$. This in itself was not unreasonable but Ackers $^{2}$ had earlier used an equally extrapolative plot to argue the case for the logarithmic resistance 'law' and against exponential 'approximations'. Moreover it was interesting to record that, at the other end of the relative roughness scale, Nikuradse rejected the result of his test with a value of $d / k=1014$ because ' . . the assumption of geometrical simularity probably did not exist'. ${ }^{19}$

74. The writers, therefore, wished to stress the very real difficulty in physical visualization of extrapolative cases following Nikuradse's procedure.

75. In conclusion, Dr Barr and Mr Smith wrote that their discussion had been quite critical of certain parts of the Paper and its background aspects--parts which many readers might not regard as the most important. They felt, in fact, that much of the Paper could be of considerable value to the practical designer and that it was to be commended as a record of a most useful piece of research. Their fear was that a position of inflexibility was being engendered in the minds of those whose interest lay more in the utilization of resistance formulae and diagrams than in critical examination of their basis and applicability.

Mr E. W. Flaxman (Messrs Binnie \& Partners) wrote that the Authors were to be congratulated upon having obtained such a large amount of data upon the roughness of mature sewers. It did not require much imagination to appreciate that the work described in the Paper must have been very unpleasant to carry out, but the Authors had persevered even after their appeal for information had met with no response. Much of the value of the Paper lay in the fact that it covered such a wide range of diameters, gradients, and materials, so that out of a welter of data it had been possible to draw broad conclusions about the general trends of sewer roughness.

77. It was interesting to compare the results now obtained with the values given by the Crimp and Bruges equation for sewers running full. In the case of a foul sewer running at about a sixth of the pipe-full capacity, the slimed area would amount to about $35 \%$ of the total surface. Using the same figures for roughness as the Authors had used in $\$ 38(0.005 \mathrm{ft}$ for the slimed portion and $0.0005 \mathrm{ft}$ for the remainder) the composite roughness came out at about $0.002 \mathrm{ft}$. Over a wide range 
of diameters, from $6 \mathrm{in}$. to $60 \mathrm{in}$., the discharge given by the Crimp and Bruges equation was consistently within $4 \%$ of the figure given by the Colebrook-White equation, being slightly conservative in the smaller diameters and slightly optimistic in the larger sizes.

78. In his original paper on the roughness of new sewers Ackers ${ }^{1}$ had written that the arbitrary application of the Crimp and Bruges equation, 'which was conservative even for new brickwork, to all forms of sewer construction has little justification'. In the light of the results now published, this criticism appeared to be a little harsh, and it seemed remarkable that a formula first published in 1894 had been so near to the mark.

79. A related subject and one on which there appeared to be little information available, was that of the hydraulic resistance of sewage pumping mains. Because a pumping main was constantly full, any sliming would have a greater effect upon the roughness factor than a similar thickness of slime in a sewer where it would generally be limited to the lower portion of the periphery. On the other hand, the growth of slime might be limited to some extent by the absence of free air in a pumping main.

80. In order to obtain some data on this question Mr Flaxman had recently carried out tests on two small diameter pumping mains conveying unscreened sewage. The first was a $9 \mathrm{in}$. diameter asbestos cement main $2500 \mathrm{ft}$ long which had been in use for about 4 years, and the second was a 5 in. diameter spun iron main $1500 \mathrm{ft}$ long which had been in use for about 10 years. In each case two test runs were carried out and the results were as shown in Table 6.

81. No high degree of accuracy could be claimed for these tests since the results depended largely on pressure gauge readings, and each main contained a number of specials, including a reflux valve. However, the results appeared to be fairly consistent and it would be interesting to know whether the Authors could provide any more information on this subject.

TABLE 6

\begin{tabular}{|c|c|c|c|c|}
\hline & & & $\begin{array}{c}\text { Velocity } \\
f t / s\end{array}$ & $\begin{array}{l}k \\
f t\end{array}$ \\
\hline $\begin{array}{l}9 \text { in. dia. A.C. main } \\
5 \text { in. dia. S.I. main }\end{array}$ & $\begin{array}{l}\text { 1st test } \\
\text { 2nd ,, } \\
\text { 1st test } \\
\text { 2nd , }\end{array}$ & 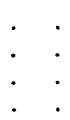 & $\begin{array}{l}2 \cdot 7 \\
2 \cdot 7 \\
3 \cdot 4 \\
3 \cdot 4\end{array}$ & $\begin{array}{l}0.002 \\
0.003 \\
0.003 \\
0.003\end{array}$ \\
\hline
\end{tabular}

The Authors were encouraged by the number of contributions to the discussion and the useful additional information which these contained, and they were very grateful.

83. Mr White asked for some differentiation between the types of sewers tested. The footnote to Table 2 indicated that all the sewers carried continual foul sewage except site 12, which took the overflow from a side-weir manhole. The $k_{s}$ value, coupled with the observed absence of slime, suggested that storm-overflow pipes and, presumably, surface-water sewers which also came into action intermittently would not slime. The other test sites were on foul sewers, except for site 5 (a combined sewer), site 13 (a ' 6 d.w.f.' sewer beyond an overflow), and site 15 (a combined sewer). Apart from the three Brighouse sites, the tests were carried out under dryweather conditions during the higher stages of the diurnal variation of flow. The depths of flow may be deduced from the hydraulic mean depths given in Table 2, where the roughness values refer to the slimed section of the sewer only. At site 5 the results show that the overall $k_{\mathrm{s}}$ value reduced under storm conditions, presumably 
because of the proportion of the wetted perimeter above the d.w.f. level not affected by slime.

84. Mr Escritt suggested that, when designing new systems, one would generally ensure self-cleansing velocities and hence the data obtained from sites with inadequate velocities should not be taken into account in recommending a $k_{\mathrm{g}}$ value. Sites $2,4,6$ and 18 had velocities under $1.5 \mathrm{ft} / \mathrm{s}$, so if brick construction was excluded but the results from sites 5 and $\mathbf{1 3}$ for the lower group of depths were included, the situation for slimed sewers was as follows:

12 results from $0.00003 \mathrm{ft}$ to $0.06 \mathrm{ft}$;

a median value of $0.004 \mathrm{ft}$;

8 results between $0.010 \mathrm{ft}$ and $0.002 \mathrm{ft}$.

85. The results given by $\mathrm{Mr}$ Clay for a very long large sewer (concrete against steel forms with the roughness ground off) in New Zealand were most interesting. After 2 months' use the average $k_{\mathrm{s}}$ value was $0.0021 \mathrm{ft}$, the 'normal' value for Class 3 concrete described by Ackers, ${ }^{3}$ although by the description it might initially have been Class 4 and had a lower $k_{\mathrm{s}}$ value; after 11 months, it had deteriorated to a $k_{a}$ value of $0.0059 \mathrm{ft}$, close to the 'normal' value for the sliming of up to $\frac{1}{4} \mathrm{in}$. thick which was observed. The corresponding data given for three pressure pipes made of $8 \mathrm{ft}$ long spun concrete pipes showed that at two of the sites, even after about a year's use, their performance was rather better than Class 4a, 'normal', when clean. At the third site, after 2 years, some deterioration was evident, but the performance was still better than the norm for slimed free-surface sewers. This could be evidence that sliming in the absence of an air/water interface was less severe, as suggested by Mr Flaxman. This agrees with the conclusions of Yang and Ried. ${ }^{9}$ The Authors hope that $\mathrm{Mr}$ Clay will continue both series of observations, to check whether or not there is any further deterioration later in the life of these schemes.

86. Mr Flaxman's tests were on relatively small pumping mains, and gave $k_{\mathrm{s}}$ values of about $0.003 \mathrm{ft}$ for asbestos cement after 4 years, and also for spun iron after 10 years. These were appreciably rougher than Mr Clay's larger, but younger, concrete mains but were still rather better than the average slimed sewer.

87. $\mathrm{Mr}$ Cassidy provided engineers with useful information about London County Council practice. The L.C.C. gave careful thought to the variation of capacity with the type of construction and the condition, since it was found that the velocities in old brick sewers were appreciably less than the values obtained by Crimp and Bruges. The L.C.C. now concluded that 'when evaluating the capacity of an existing system more note would have to be taken of the condition of the individual sewers'. This reflected the Authors' views, and it is hoped that all drainage engineers accepted the fact that no single roughness coefficient could represent the wide range of conditions to be met. Despite Mr Flaxman's comment, the first Author saw no reason for withdrawing his earlier comment: the arbitrary application of the Crimp and Bruges equation to all forms of sewer construction has little justification.

88. A clarification of the terms 'good', 'normal', and 'poor' in Table 3 of the original paper had been requested, and perhaps a similar clarification in respect of Table III of the paper by Ackers ${ }^{3}$ was needed. A range of roughness values had been given, first because the experimental data upon which the recommendations were based inevitably showed scatter, and second, because a given class of material, construction or condition, contained some examples which were better and some which were worse than average. An exact statistical description of the three terms was not possible because the data were relatively sparse, but they were probably about the 10,50 , and 90 percentiles. In the case of slimed sewers, the terms referred to the slimed surface: in new sewers, they referred to the initial workmanship.

89. Exponential equations of the form

$$
V=K m^{\alpha} i^{\beta}
$$

were common in the literature of fluid resistance, but the Authors suggested that $\mathrm{Mr}$ 
Escritt was mistaken in suggesting that theoretically $\alpha$ should be a constant and $\beta$ should be 0.5 . It was implicit in the theory of turbulence that fluid friction could not be accurately represented by a single equation of this type, and this accounted for the appearance of logarithmic terms in modern formulae. Exponential equations were no more than approximations to a more general relationship, although it was generally acknowledged that they could provide fairly good approximations over strictly limited ranges.

90. For example, the Manning equation was a good one under rough turbulent conditions for a certain range of relative roughness, i.e. when $V k_{\mathrm{s}}>0.01 \mathrm{ft}^{2} / \mathrm{s}$ (for water at ordinary temperature) and $7<m / k_{\mathrm{s}}<130$ (see Ackers ${ }^{2}$ ). Within this range, the Manning coefficient could be converted to an equivalent sand toughness, or vice versa, through

$$
n=\frac{1}{32} k_{\mathrm{s}}{ }^{1 / 6} \text { (ft s units). }
$$

Thus the Crimp and Bruges equation, given by $n=0.012$, corresponded to $k_{\mathrm{s}}=0.0033 \mathrm{ft}$ and gave results agreeing with the general Colebrook-White equation for that $k_{\mathrm{s}}$ value within $2 \%$, provided that the velocity exceeded $3 \mathrm{ft} / \mathrm{s}$ and the hydraulic mean depth was between $0.02 \mathrm{ft}$ and $0.4 \mathrm{ft}$ (sewer diameters up to $18 \mathrm{in}$.). The example given by Mr Flaxman in $\S 77$ and by Mr Cassidy in $\S 61$, should be viewed in this context.

91. It was also shown in Ackers' Appendix $1 \mathbf{I}^{2}$ that exponential equivalents to a turbulent transition formulae of the Colebrook-White form would have exponents linked through

$$
\begin{gathered}
\alpha-\beta \propto \frac{\sqrt{ }(2 g)}{C} \\
\frac{\alpha+1-3 \beta}{\beta-\frac{1}{2}} \propto \frac{V k_{\mathrm{s}}}{\nu} \frac{\sqrt{ }(2 g)}{C} .
\end{gathered}
$$

These were equivalent to

$$
\frac{\alpha-\frac{1}{2}}{\beta-\frac{1}{2}}-3 \propto R e_{*}
$$

where $R e_{*}$, the roughness (or wall) Reynolds number is given by

$$
R e_{*}=k_{\mathrm{s}} \frac{\sqrt{ }(g m i)}{v}
$$

92. Thus as $R e_{*}$ increased (i.e. rougher, larger, steeper and/or less viscous), $\left(\beta-\frac{1}{2}\right)$ approached zero as in the Manning and similar rough turbulent equations. This is the 'square Jaw' zone where head losses are proportional to the square of the velocity. As $R e_{*}$ reduced $\left(\alpha-\frac{1}{2}\right)$ approached $3\left(\beta-\frac{1}{2}\right)$. Hence for smooth pipes when $R e_{*}=0,3 \dot{\beta}-\alpha=1$. These trends were noticeable in the four power law approximations given by Mr Escritt (Table 4), his Section A equation having 'smooth turbulent' exponents and his Section D equation having 'rough turbulent' exponents.

93. Bearing in mind the restricted range of application of such exponential equations there appeared to be no advantage in them. The Author questioned the multiplicity of formulae when a single one would suffice. A point to be considered with power laws was that an apparently insignificant rounding-off of the exponents could have a big effect on the resultant velocity figure, mainly because $i$ was not close to unity. Although Mr Escritt's four equations looked reasonable, the results they gave were somewhat anomalous, as would be seen from Table 7.

94. The reply to Dr Barr and Mr Smith was left to the last because their comments were on more academic aspects. They had implied that the Hydraulics Research Station's efforts towards bringing the Colebrook-White equation into engineering use could stultify further work in this field. However, it was hoped by the Authors that this would not occur. As the first Author wrote ${ }^{3}$ in $1958, \ldots$ the evidence 
TABLE 7: Velocities (FT/S) BY ESCRITT'S FOUR EQUATIONS WhEN $m=0.125$ (6 IN. PIPE) AND $i=1 / 1000$

\begin{tabular}{|c|c|c|c|}
\hline & & $\begin{array}{l}\text { 'Average' } \\
\text { formula }\end{array}$ & $\begin{array}{l}\text { 'Design' } \\
\text { formula }\end{array}$ \\
\hline $\begin{array}{l}\text { A } . \\
\text { B } \\
\text { C } \\
\text { D } .\end{array}$ & 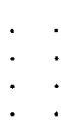 & $\begin{array}{l}1.09 \\
1.05 \\
1.12 \\
0.93\end{array}$ & $\begin{array}{l}1 \cdot 10 \\
1.00 \\
0.92 \\
0.84\end{array}$ \\
\hline
\end{tabular}

given in support of the Colebrook-White transition formula for commercial conduits and pipes fully justifies its adoption for design purposes, though in course of time further refinements in knowledge may lead to improvements and it may then be superseded.' It is to be hoped that research will continue into the many aspects of fluid resistance where uncertainty remains, for example, the dependence of the transition function on roughness type, the relationship between roughness geometry and roughness coefficient, the composite effect of dissimilar roughness, the influence of crosssectional shape, and the effects of a free surface.

95. One of the main points raised by Dr Barr and Mr Smith was that the three dimensionless parameters deduced by Ackers $^{2}$ could be derived from basic reasoning without reference to a definitive friction equation. It was proper for them to emphasize this point if they felt it was not sufficiently clearly brought out in the first Author's previous papers (see for example Ackers ${ }^{2}$, p. 13). Barr and Smith also drew attention to the extension of the curves for $k_{\mathrm{B}}=0.5 \mathrm{ft}$ in Fig. 5 to an unreasonable $m / k_{\mathrm{s}}$ value. Without further research on very rough surfaces it was not possible to define a lower limit for $m / k_{\mathbf{s}}$. In preparing Hydraulics Research Paper No. 2, the limit was arbitrarily set at unity, and on this basis at least the lower group of curves in Fig. 5 should not have been extended for diameters less than 24 in. In this context, Colebrook's Paper dealing with unlined rock tunnels was of interest. It contained several test data for $m / k_{\mathrm{s}}$ values below about ten, ranging down to about three (see Colebrook ${ }^{20}$, Fig. 8).

96. In conclusion, the Authors wished to thank those who had contributed to the discussion, not only for the interest they had shown but also because of the value of their comments and additional experimental data. It was to be hoped that many more engineers would follow their example and make measurements of flow resistance whenever circumstances permitted.

\section{REFERENCES ,}

13. Allen J. Flow of incompressible fluids through corrugated pipes. Proc. Inst civ. Engrs 1964, 28 (May), 31-38.

14. Johnson S. P. A survey of flow calculation methods. Preprinted Papers and Programme. A.S.M.E. Summer Meeting, June 1934, 98.

15. Rouse H. Evaluation of boundary roughness. Proc. Second Hydraulics Conf., Iowa, 1942, Bull. 27, No. 400, Univ. of Iowa, 105-116.

16. LanghaAR H. L. Dimensional analysis and theory of models. John Wiley, New York, 1951.

17. Streeter V. L. Fluid mechanics. 3rd edn, McGraw Hill, New York, 1962.

18. Powell R. W. Diagram determines pipe sizes directly. Civil Engineering (New York), 1950, 20 (September), 45-46.

19. NikURADSE J. Laws of flow in rough pipes. N.A.C.A. Tech. Memorandum 1292 (Translation of Stromurnsgesetze im rauher Rohren).

20. Colzbrook C. F. The flow of water in unlined, lined, and partly lined rock tunnels. Proc. Instn civ. Engrs, 1958, 11 (Sept.), 103-132. 